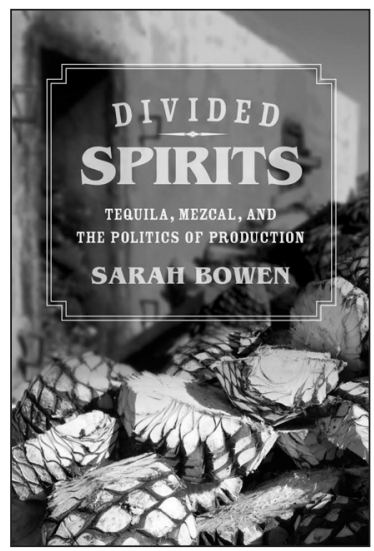

\title{
SARAH BOWEN
}

Divided Spirits. Tequila, Mezcal, and The

Politics of Production

OAKLAND: University of California Press

AÑO: 2015

ISBN: 978-0-520-28104-2

PÁGINAS: 256

\section{OLGA I. MANCHA CÁCERES / UNIVERSIDAD COMPLUTENSE DE MADRID}

\section{Reseña}

Para Igor de Garine, la alimentación ha sido un asunto de interés específico para la antropología desde los años treinta del siglo pasado (1999: 14-15) e, independientemente del enfoque o perspectiva empleados, ha sido ubicada en el centro de los procesos de estructuración o desestructuración del orden económico y social (Gracia, 1996).

Sarah Bowen, profesora asociada del Departamento de Sociología y Antropología de la Universidad Estatal de Carolina del Norte, presenta en Divided Spirits. Tequila, Mezcal, and The Politics of Production, el resultado de algo más de una década de trabajo sobre las denominaciones de origen (DO) en México, Francia y Estados Unidos, en el que nos presenta un profundo análisis del complejo mundo de la producción y comercialización del tequila y el mezcal — dos productos identitarios de México-, las dinámicas sociales, económicas y políticas que promueven y el papel de sus múltiples y desiguales actores involucrados. El texto va más allá de la descripción de unos productos locales y nos desvela el entramado de redes y relaciones multisituadas que la producción y comercialización de estas bebidas suscitan. El profundo conocimiento de Bowen sobre los modelos de DO e Indicaciones Geográficas (IG) europeos, especialmente de España, Francia e Italia, permiten a la autora llevar a cabo un análisis comparativo de la relación existente entre producción calificada, desarrollo rural, des- 
igualdad, conservación de la biodiversidad y protección del patrimonio cultural, mostrándonos el panorama más reciente del fenómeno en América y Europa. Bowen analiza a los actores a lo largo de las cadenas productivas de mezcal y de tequila, en cada uno de sus niveles, así como la interrelación de estos. En cada una de estas unidades de análisis, la autora detalla los contextos regulatorio, político e institucional y los contextos local, regional y transnacional en los que se mueven dichos actores.

Un alimento es la materialización directa de una cultura. En sí mismo expresa la adaptación de un grupo humano a su medio físico y da cuenta de todo un repertorio de creencias y técnicas transmitidas de generación en generación. Necesariamente, el alimento incluye un compendio de saber-hacer, de costumbres ancladas territorialmente que se imbrican con otros elementos culturales como son los modos de organización social y política. Así, Feuerbach en 1850 escribió «El hombre es lo que come» (Der Mensch ist, was er isst) (Lemke, 2011: 1), reivindicando la necesidad del acceso del proletariado a una buena alimentación. Mirando más allá de la nutrición, el pensador alemán ve la importancia antropológica del alimento, pues lo que comemos nos dota de identidad, nos significa.

Este modelo productivo local coexiste con un régimen corporativo alimentario industrial, apoyado y sostenido por los gobiernos neoliberales y el capital corporativo transnacional que McMichael (2002) ha denominado "food from nowhere» (alimentos de ningún lugar), producto del proceso de globalización, que desterritorializa e industrializa la producción de alimentos y debilita los sentimientos de pertenencia y propiedad de los productores locales de alimentos.

Esta interpretación dicotómica ha sido cuestionada por Manhire et al. (2012), al caracterizar lo que denominan «alimentos de algún lugar», productos glocales, dado que transitan entre lo global y lo local, y que se presentan como "sostenibles, locales, de comercio justo, certificados como ecológicos, denominación de origen o indicación geográfica protegida» (productos más integrados cultural y ecológicamente) al mismo tiempo que abarcan a grandes explotaciones y corporaciones agrícolas, redes de comercio global y minorista, entidades certificadoras y mercados exclusivos (que los insertan en dinámicas globalizadas). Aplicar esta perspectiva teórica al texto de Sarah Bowen nos permite entenderlo en toda su amplitud.

Las DO e IG son productos colectivos administrados por actores locales que avalan la procedencia y características de un producto, para tranquilizar a un consumidor. La calidad del producto viene derivada del terroir, el terruño, "el sabor del lugar» (p.11), entendido como el conjunto de características especiales derivadas de la geografía, la geología y el clima de un determinado territorio, así como de las actividades y prácti- 
cas agrícolas que identifican a unos actores y unas estructuras sociales. DO e IG proporcionan un medio para proteger el entorno ambiental, el conocimiento campesino y las prácticas culturales, además de una herramienta para garantizar que los actores locales puedan seguir controlando la producción y la venta local al mismo tiempo que el acceso a un consumidor externo, aprovechando el contexto económico global.

Estas herramientas, que han demostrado su utilidad en el caso europeo, en el caso del tequila y el mezcal, sin embargo, son una estrategia fagocitadora emprendida por las grandes corporaciones de bebidas alcohólicas, quienes se asocian o directamente compran empresas propiedad de mexicanos, se apropian de la etiqueta e imponen las normas de la producción capitalista al saber-hacer ancestral. Normas de producción estandarizadas que implican la inversión de grandes capitales que ponen en riesgo la supervivencia de una miríada de pequeños productores locales que no pueden acometerlas, generando dinámicas de exclusión y éxodo rural.

La autora desvela cómo los intereses de las corporaciones internacionales terminan prevaleciendo sobre unos productos «símbolos» de la identidad y cultura mexicana. La fagocitación que realiza el mercado globalizado de bebidas alcohólicas sobre las producciones locales promueve la implantación de un sistema agroindustrial productivista, concentrando, industrializando y estandarizando dichas producciones, monopolizando el cultivo del agave y expulsando de la cadena de suministro a los pequeños productores, así como implantando modelos mecanizados de cultivo y uso de agrotóxicos. Las grandes compañías no reconocen ninguna de las características que el terroir dota al producto, pues las prácticas tradicionales de cultivo se oponen a la rentabilidad. No interesa ni la autenticidad del proceso ni la calidad del agave producido según el acervo cultural.

Sarah Bowen se pregunta por el papel que las autoridades mexicanas tienen, no solo en la preservación de un conocimiento tradicional que ha caracterizado estos productos, sino también en la promoción de una industria que, bien gestionada, podría ser un instrumento para el desarrollo territorial sostenible y el empoderamiento de productores locales, llegando a la conclusión de que las dinámicas de poder existentes en los contextos del Sur Global impiden a los actores locales mantener el control sobre su producto, a diferencia de lo que ha ocurrido en Europa, con una mayor trayectoria en la protección y otros modelos de gobernanza. Así, la mera copia de los modelos europeos ha sido instrumentalizada por unos actores transnacionales poderosos.

La obra cuenta con siete capítulos. El primero, The promise of place, da comienzo con un "análisis de situación» al estilo de Gluckman, a partir del cual la autora, muy acertadamente, nos ubica en el problema y en 
los actores involucrados, de los que tratará pormenorizadamente en las páginas siguientes. Bowen desvela la tensa relación entre los actores «globales» de la producción y comercialización de las bebidas fabricadas a partir del agave y los pequeños productores, sus intereses contrapuestos, y cómo la «identidad» es un concepto instrumentalizado en función de intereses ajenos a la protección de la diversidad o el patrimonio cultural. A partir de esta escena, el capítulo da cuenta de la historia del tequila y el mezcal, sus diferencias y especificidades, las figuras de protección asociadas a ellos y su s alcances, para después ubicar la discusión sobre las DO en el contexto europeo y global y sus posibilidades para un desarrollo sostenible y justo, además de para la preservación cultural.

En el capítulo segundo, From the Fields to Your Glass, la autora detalla la historia del mezcal y el tequila en México y el papel de ambos productos en la propia historia del país, en un relato que recuerda a Dulzura y Poder de Sidney Mintz, al trascender las fronteras mexicanas e insertar los destilados del agave en la economía política de la globalización, contribuyendo a entender la inserción de estas bebidas en el mundo actual y las dinámicas identitarias asociadas a los mismos.

El tercer capítulo, titulado Whose Rules Rule? Creating and Defining Tequila Quality, pormenoriza en el tequila, el primer producto protegido por una DO en México en 1974. Narra el proceso de conformación de la DO y cómo progresivamente las grandes corporaciones fueron promoviendo unos estándares que se alejaban de la producción tradicional de tequila, con la aparición de conflictos, algunos especialmente violentos, que trascienden lo local y se convierten en asunto de Estado. Bowen es especialmente crítica aquí con el Estado mexicano, al que ubica del lado de los intereses de las grandes corporaciones.

El capítulo cuarto, The Heart of The Agave: Farming in Tequila Country, y el quinto, Making Mezcal in the Shadow of the Denomination of Origin, etnografían los contextos locales de producción de tequila y mezcal respectivamente, aportando una visión muy clara sobre las condiciones de vida y trabajo de los pequeños productores, su vulnerabilidad histórica y cómo las DO no han contribuido a mejorar su nivel de vida, más aún en el caso del mezcal, considerado históricamente un producto «periférico», cuya protección no llegó hasta 1994.

El capítulo seis, Hipsters, Hope, and the Future of Artisanal Mezcal, presenta una nueva era del mezcal propiciada por la valorización que determinados colectivos y movimientos sociales recientes (bipsters, Slow Food) hacen, rechazando el consumismo desmedido de las marcas «globales», optando por los productos locales, con identidad, ecológicos o el comercio justo. En este capítulo muestra las conexiones directas que se esta- 
blecen entre productores-consumidores y las potencialidades de un modelo de circuito corto para el desarrollo local y la preservación patrimonial.

Concluye el capítulo siete, Looking Forward, con una mirada optimista acerca del papel que el crecimiento del mercado de los mezcales y tequilas tradicionales tiene para empoderar a los pequeños productores, aunque reconoce la necesidad de un cambio de actitud de los actores políticos, que debería orientarse más a protegerlos de las grandes corporaciones a la vez que exigirles a estas mayor justicia y trasparencia en sus prácticas de trabajo y en el precio por el agave, cambiando su papel productivista y extractivo de bienes y saberes por uno nuevo como sostenedoras de «el legado de todos los mexicanos».

Tras los capítulos, el texto incluye un apéndice metodológico de gran utilidad para entender el tipo de etnografía multisituada llevada a cabo por Bowen para discernir el complejo entramado de actores y relaciones del mundo del tequila y el mezcal.

Concluimos esta reseña recomendando la lectura del libro de Sarah Bowen, quien es capaz de desvelar todo el complejo mundo del mezcal y el tequila en su profunda complejidad, con una lectura fresca que combina la etnografía con unos certeros análisis de dinámicas globales, ayudando a desvelar los procesos de homogeneización cultural y las resistencias locales, y en cierto sentido translocales, (y aquí vuelvo a la idea de Feuerbach en su sentido ampliado, pensando en los hipsters que se acercan al mercado agroecológico de Matadero, en Madrid, que beben un mezcal o una cerveza artesanos, para significarse) de la globalización.

\section{Referencias bibliográficas}

De Garine, I. (1999). Antropología de la alimentación: entre Naturaleza y Cultura. Congreso Internacional de Alimentación y Cultura, 1998. Madrid: Museo Nacional de Antropología. En http://valencianmuseumethnology.org/userfiles/file/Ernaehrung_und_Kultur.pdf.

Gracia Arnáiz, M. (1996). Paradojas de la alimentación contemporánea. Barcelona: Icaria editorial; Institut Català d'Antropologia.

Lemke, H. (2011). Der Mensch ist, was er isst. Ludwig Feuerbach als Vordenker der Gastrosophie. EPIKUR - Journal für Gastrosophie, 01: 1-12. En http://www.epikur-journal.at/interactivist/frontend/downloadDoc.asp?file=LudwigFeuerbach\%2Epdf\&typ=.pdf\&id=00175\&chk=329175.

Manhire, J; Moller, H.; Barber, A.; Saunders, C.; MacLeod; C.; Rosin, C.; Lucock, D.; Post, E.; Ombler, F.; Campbell, H.; Benge, J.; Reid, J.; Hunt, L.; Hansen, P.; Carey, P.; Rotarangi, S.; Ford, S. y Barr, T. (2012). The New Zealand Sustainability Dashboard: Unified monitoring and learning for sustainable agriculture in New Zealand. ARGOS Working Paper, 8. 40 + vi.

McMichael, P. (2002). La restructuration globale des systems agro-alimentaires. Mondes en Developpment, 30(117): 45- 54 